\title{
El Poder Simbólico de las Gremiales Ganaderos en el Uruguay Contemporáneo
}

\section{Introducción}

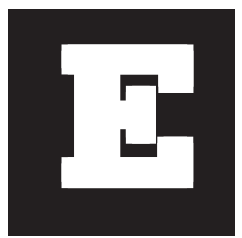

n este artículo se buscará explorar el poder de las Gremiales Ganaderas en Uruguay - Asociación Rural del Uruguay (en adelante ARU) y Federación Rural (en adelante FRU) ${ }^{1}$ mediante una aproximación a la dimensión simbólica de la realidad social, observando como estas gremiales logran, a pesar de la pérdida de su poder económico, restablecer y ampliar su poder mediante la operación simbólica de imponer, a buena parte de las elites dirigente y de la sociedad, una visión del mundo rural que legitima su poder y su posición social de privilegio. De esta forma, los ganaderos pueden presentar sus intereses particulares como intereses generales de la nación, obteniendo continuos beneficios de las políticas públicas dirigidas al sector.

En este sentido, se considera que los elementos simbólicos que están en juego en el campo social agrario y las estrategias desplegadas por las Gremiales Ganaderas para preservar sus posiciones de poder tienen, en el caso específico de Uruguay, como uno de sus principales "enjeu", la

* Professor do Departamento de Sociologia - Universidad de la República (Uruguai), Doutor em Sociologia - UFRGS, coordenador geral da Rede de Desenvolvimento Territorial e Integração Regional (ReDeTIR).

** Professora da Faculdade de Ciências Sociais da UdelaR (Uruguai).

1 Históricamente estas dos organizaciones han representado los intereses de los grandes estancieros dedicados a la ganadería. Si bien ambas organizaciones presentan matices, los estudios sobre ellas sostienen que ambas no presentan divergencias importantes y en general representan a dicho grupo social (Barrán y Nahum, 1981; Astori, 1979; Piñeiro, 1992; Riella, 2002). Esto permite, a los efectos de este trabajo, tomar los discursos de ambas organizaciones como una sola unidad de análisis. 
determinación de las políticas agrarias. Ello se debe a que la intervención del Estado, mediante la legislación, las políticas públicas y las políticas tributarias, cristaliza las posiciones sociales, objetivando el poder de cada agente y distribuyendo el capital simbólico. La obtención de este último tipo de capital es un elemento imprescindible para las luchas simbólicas en la reproducción social de los agentes en los conflictos agrarios en Uruguay.

La estrategia llevada adelante por las gremiales ganaderas está centrada en lo que denominamos como la recreación permanente del "mito" del país ganadero, que busca imponer como único destino posible para el Uruguay la producción de carne y lana. A través de su prédica constante lograron que esta idea se arraigara durante décadas en los amplios sectores sociales. Pero con el advenimiento de la democracia a mediados de los 80 y los cambios en el mundo económico, esta percepción sobre el destino del país fue desvaneciéndose. Sin embargo, como mostramos en este artículo, en la década de los 90 las gremiales ganaderas lograron revertir esta tendencia y reafirmar ese mito de país ganadero así como imponer esa forma de ver el desarrollo del país a varios integrantes de las élites dirigentes y a la opinión pública. Ello generó una situación algo paradójica en tanto un grupo tradicional y con poco dinamismo económico, se revigoriza corporativamente llegando a ser uno de los grupos que más aportó a la legitimación social de los principios del modelo neoliberal en el país. Esto también le permite dentro de los grupos dominantes, tener una legitimación mayor que otras fracciones con importante poder económico, otorgándole un poder simbólico mayor. Esta inconsistencia de status entre su poder simbólico y su poder político es una fuente permanente de conflictos entre las gremiales, el gobierno y otras facciones del capital, sobre todo las vinculadas al sector financiero.

En la última década, ese poder simbólico les permitió un sistemático tratamiento diferencial del Estado que les ha posibilitado mantener un férreo control de la tierra, mantener la ineficiencia cíclica de su sistema productivo estancado por más de 50 años y ocultar las graves desigualdades sociales que existen en la sociedad rural. 
La pertinencia de tratar este tema en este dossier se basa en el supuesto de que la construcción social de los territorios rurales en nuestro país se asienta, en gran medida, en esta percepción impuesta por el poder simbólico de los grandes ganaderos, la cual determina las formas legítimas de apropiación y uso de la tierra que llevan a una permanente reproducción de las relaciones de poder en el campo social agrario.

Desde el punto de vista metodológico, recurrimos al análisis de discursos para poder de-construir los principales elementos que componen su estrategia discursiva, y observar los mecanismos socio-semánticos que les permitieron "mimetizar" sus intereses con el interés y el destino de la nación y ubicarse como el eje del desarrollo económico y social del país. Un presupuesto básico para analizar las relaciones de poder en la esfera de construcción simbólica de la realidad social, como afirma Bourdieu (1985), es que en ella "hablar" es "hacer". En este sentido, el material analizado lo constituyen los discursos anuales del presidente de cada una de las dos instituciones mencionadas realizados entre 1985 y 2000.

Por último, es importante considerar que, si bien sólo se trata el caso uruguayo, buena parte de la estrategia simbólica desplegada por estas gremiales también se puede observar en el resto de las gremiales de grandes estancieros y hacendados de la región. De esta forma, el presente trabajo podría ser un aporte para una futura mirada comparada para el contexto regional y un análisis de cómo estas estrategias pueden estar incidiendo en el proceso de integración regional. ${ }^{2}$

\section{La especificidad de las luchas simbólicas en el campo social agrario}

Las luchas simbólicas que se despliegan en el campo social agrario son producto del enfrentamiento de las estrategias que despliegan los distintos 
agentes para imponer al resto su visión particular del "mundo rural" como una visión universal de ese mundo. Es decir, que los agentes buscan tener el poder simbólico para "poder hacer el mundo", para imponer e inculcar los principios de percepción de la realidad rural, y "particularmente para preservar o transformar los principios establecidos de unión y separación, de asociación y disociación" (Bourdieu, 1994, p. 95) que operan en la construcción social de la realidad. Esto les permite describir y definir los grupos, las instituciones y los problemas de la cuestión agraria del país. Para estudiar las estrategias simbólicas de los agentes debemos tener muy presente que en esta dimensión de la realidad social "decir es hacer". La palabra y los argumentos que con ella se esgrimen son prácticas en tanto entrelazan redes sociales de pertenencia, de alianzas, de proximidades y de conflictos en un sistema de sentido que refiere a las posiciones objetivas de competencia entre los agentes.

Desde esta perspectiva analizaremos las prácticas discursivas de las Gremiales Ganaderas como parte central de su estrategia simbólica ${ }^{3}$ para imponer su hegemonía en el campo social agrario. Como señaláramos anteriormente, creemos que la construcción social del territorio en nuestro país se asienta en la forma de percepción impuesta por el poder simbólico de los grandes ganaderos, que han hecho de sus formas particulares de apropiación y uso de la tierra la única forma posible y legítima. Ello implica que cualquier alterativa o intento de modificar esta concepción del territorio se presenta como "ilegítima", como un desorden al orden natural de las cosas y por tanto con una propuesta irresponsable e irracional. Por esta razón, el análisis de dichas estrategias cumple un papel relevante en la investigación sociológica y, en particular, para los análisis espaciales que buscan incorporar la noción de "territorio" como algo socialmente construido. Las formas simbólicas con las que se percibe el espacio están en la génesis de la construcción del territorio

3 El concepto de estrategias remite a la necesidad que los agentes sociales tienen de generar su propia producción y reproducción social, en una sociedad que está en un proceso permanente de mutación y cambio de las posiciones sociales estatuidas socialmente, bajo una dinámica que alberga movimientos estructurantes y contingentes. 
y determinan su forma de apropiación legítima, cristalizando, en el caso que nos ocupa, las relaciones de poder en el campo social agrario.

Para el análisis de las prácticas discursivas partimos del supuesto de que las organizaciones sociales, gremiales y corporativas están siempre inmersas en luchas simbólicas ya que en ellas está en juego la realización objetiva de sus intereses a largo plazo. ${ }^{4}$ Utilizando los términos de Merton, podríamos afirmar que, más allá de la función manifiesta de una organización - gremial, comercial, profesional -, siempre hay una función latente que procura imponer la "visión del mundo" del grupo que se representa. Esto puede ir incluso contra la voluntad manifiesta de los representantes, ya que se expresará a través de las disposiciones instaladas en sus habitus y que remiten al principio de "no-conciencia" de estos fenómenos (Bourdieu, Chamboredon, Passeron, 1995).

Por esta razón, los discursos de sus dirigentes no deben ser considerados como meras "opiniones subjetivas" sino como "hechos objetivos" ya que representan el punto de vista de la posición social que ocupa ese grupo. En consecuencia, puede plantearse que no hay nada más objetivo que la subjetividad ya que ella expresa la internalización de las condiciones materiales de existencia. "Las representaciones de los grupos de interés no son meras perversidades y ocultamientos, son representaciones subjetivas de sus posiciones estructurales, sus representaciones en este sentido deben considerarse como objetivas" (Bourdieu, 1993). De este modo, en el discurso de las gremiales ganaderas encontraremos reflejada crudamente la visión que tienen desde el lugar que ocupan, visión que será expuesta con la sinceridad inconsciente de quien no es capaz de reconocer su punto de vista como uno más y lo expresa sin ocultamientos. En consecuencia, en las prácticas discursivas de estos agentes podremos encontrar claramente expresado su poder, sus alianzas, sus conflictos y lo que nos permite comprender cabalmente su estrategia simbólica de reproducción social.

4 No se trata aquí de asumir una perspectiva que disuelva la distinción entre las prácticas discursivas y no discursivas llevando a una "inflación del discurso", como lo señala Anderson (1988) cuando critica los trabajos de Laclau y Mouffe. 
También se debe tener presente que la capacidad de estos agentes de ir imponiendo su punto de vista en el campo social agrario no es necesariamente equivalente a su poder económico. Esto depende en gran medida de la acumulación de capital simbólico y de la estrategia de acción que lleven adelante las gremiales en cada uno de los conflictos (Riella, 2002).

Para reconstruir la estrategia simbólica de las Gremiales Ganaderas consideramos un periodo de análisis suficientemente amplio como para poder incorporar los elementos constitutivos de las mismas. Por esta razón, analizamos los discursos de las gremiales ganaderas - ARU y FRU - entre los años 1985 y $2000 .^{5}$

\section{El contexto de los discursos}

A mediados de los años ochenta, cuando comienza el proceso de redemocratización del país, la legitimidad de las gremiales ganaderas y los intereses de los grandes estancieros estaban en ciernes. Más de una década de apoyo explícito al gobierno militar, una reducción de su importancia económica y un fuerte cuestionamiento por parte de intelectuales y técnicos a su modelo de explotación, al que se le identificaba como uno de los principales causantes de los problemas económicos que arrestaba el país desde décadas atrás, cuestionaban el poder que los ganaderos sustentaban en la sociedad uruguaya y abrieron el camino a las propuestas que buscaban revisar las bases de la estructura agraria en la que se asentaba su poder. Este tema fue objeto de un amplio debate político a la salida de la dictadura que desembocó en un "estado de ánimo" de la sociedad de cierta adversidad hacia los ganaderos. En 1985, se dio entonces un consenso implícito sobre la necesidad de buscar algún cambio en las estructuras agrarias por lo que los partidos tradicionales se vieron en la obligación, objetivando este estado de ánimo colectivo, de introducir en sus plataformas electorales de esos 
comicios alguna medida en esa dirección.

Ante este escenario, las gremiales ganaderas comenzaron a desplegar una amplia y sostenida estrategia de relegitimación de su posición e intereses. Si bien, en líneas generales, los argumentos utilizados por la ARU y FRU para reafirmar y recrear su visión del mundo rural fueron construidos por su paciente trabajo de más de un siglo, el período analizado se constituirá en una dura prueba para lograr mantener en pie esa construcción. En este periodo, las organizaciones ganaderas deberán competir con otras corporaciones y organizaciones sociales para legitimar sus reclamos ante una opinión pública y una sociedad civil que los identificaba como muy asociados al régimen militar ${ }^{6}$ y como uno de los principales culpables de los problemas económicos del país (Bruera, Filgueira, Gonzalez, 1992).

En este escenario, los intereses ganaderos debían competir con el resto de las organizaciones de la sociedad civil para dirigir las políticas del primer gobierno democrático, el cual enfrentaba, después de 15 años de dictadura, un cúmulo de reclamos económicos y sociales.

Para esta batalla, los ganaderos contaban con algunas ventajas y con algunas desventajas. Las principales desventajas eran su estancamiento económico, su explícito apoyo a los sucesivos gobiernos militares y su entusiasta adhesión a sus medidas de liberalización de los mercados agrícolas llevadas adelante abruptamente en 1979. Las drásticas consecuencias sociales que tuvieron estas medidas en el medio rural, su falta de dinamismo económico y su vinculación pública con la dictadura contribuyeron en su conjunto a que los primeros años de la transición democrática los encontrara con un fuerte debilitamiento de su poder simbólico.

Sus ventajas consistían en que, aunque menguados, seguían manteniendo su poder económico y una sintonía ideológica con el gobierno electo democráticamente, en torno a los lineamientos generales de las

6 Estas circunstancias se verán algo atenuadas en 1985, en tanto que la FRU comenzó a fines de 1980 a realizar una acción pública contra los militares que la llevará a una ruptura pública con el régimen en 1982. En ese mismo tiempo, dos años antes de caer la dictadura, la ARU comenzó un discreto alejamiento del gobierno militar. 
políticas económicas y a la profundización del modelo neoliberal parcialmente impuesto por la dictadura.

En este contexto, debieron enfrentar en el campo de poder a enemigos muy poderosos para sus intereses a corto plazo, como al capital financiero que tenía una creciente y determinante influencia en este campo, a la fracción industrial frigorífica y a la propia necesidad recaudatoria del Estado.

En el terreno de las fuerzas populares, debían enfrentarse a las demandas de los trabajadores urbanos en apoyo a la incipiente agremiación rural y a la redistribución de las tierras, impulsada por las fuerzas políticas de izquierda con el apoyo de recientes organizaciones de colonos y pequeños productores.

Ante estos adversarios, en un contexto democrático, no existe otra arma que reafirmar e incrementar su poder simbólico. La primera estrategia discursiva para reforzar el poder simbólico es "hacer entender" que, más allá de los cambios sociales, políticos y económicos ocurridos en el país y en el mundo, y a pesar de los tropiezos "coyunturales", "el país sigue siendo un país agropecuario".

Las circunstancias referidas indican la urgencia simbólica a la que se enfrentaron los ganaderos, necesitando recomponer el sitial de privilegio que ocupaban en las representaciones del sector y restaurar la creencia de su importancia estratégica y el ineluctable destino agropecuario del país.

\section{La recreación del mito del país ganadero}

La estrategia simbólica de las organizaciones ganaderas está dirigida, en términos generales, a la reconstrucción y actualización del "mito del país ganadero", base de su poder simbólico en la sociedad uruguaya. Esta estrategia simbólica busca encadenar nuevas y viejas representaciones en una sucesión de equivalencias para contar con un "artefacto social bien fundado", imprescindible en su estrategia para mantener su hegemonía en 
el campo social agrario y aumentar su influencia en el campo de poder de la sociedad uruguaya.

Para estudiar los componentes de esta estrategia comenzaremos por analizar los distintos elementos de los discursos ${ }^{7}$ de ambas instituciones, referidos al "sector agrario" y al "papel" que la ganadería ocupa en la sociedad. Estas afirmaciones conforman la base del mito de que Uruguay tiene como único modelo posible de desarrollo la ganadería extensiva.

\subsection{Asociaciones y equivalencias simbólicas}

En el análisis que estamos realizando debemos prestar especial atención a las articulaciones u oposiciones de intereses que se presentan en los discursos, porque ello nos informará de una manera particularmente eficaz sobre las alianzas y conflictos de las organizaciones ganaderas, tanto en el campo social agrario como en el campo de poder. En esta perspectiva, los procesos de asociación y equivalencia son significativos para el análisis, en tanto que de ellos emergen relaciones referentes, símbolos o ideas que, por la rigidez y fijeza de sus elementos, pueden interpretarse como medidas de la intensidad o fuerza de una representación, creencia o convicción. En general, las representaciones simbólicas no son más que el producto cultural de asociaciones muy elaboradas y de tradiciones socialmente consolidadas que reflejan determinada relación de fuerza entre los agentes que "viven" en esa realidad.

En el caso que nos ocupa, esto se puede traducir en las siguientes asociaciones que intentan imponerse como equivalencias en los discursos de las corporaciones ganaderas: Agro = País = Riqueza. Esta fórmula es simbólica en tanto que el Agro (re)presenta algo más que su significado inmediato y obvio; justamente el carácter simbólico proviene de las unidades significantes - País y Riqueza -, las que provocan una especie de dualidad

7 Todas las citas de este artículo, en que no aparece especificada la fuente, provienen de los discursos de los Presidentes de la Federación Rural o de la Asociación Rural del Uruguay para el año e institución a la cual se hace referencia en el párrafo en que está inserta dicha cita. 
semántica, solidaria e indivisible, basada en la asociación de ideas de uso muy generalizado. La constancia, redundancia y coherencia en los significantes con que las organizaciones ganaderas articulan los elementos de su discurso, permite vislumbrar la presencia de un sistema de codificación rígido, de fuerte normatividad. En este sentido, señala Bourdieu (1986, p. 84) que,

la codificación es una operación de puesta en orden simbólico o del mantenimiento del orden simbólico (...), la codificación produce el efecto de la formalización, terminar con lo impreciso, con lo vago, con las fronteras mal trazadas (...), la codificación hace las cosas simples, claras, comunicables; hace posible un consenso controlado por el sentido.

Los códigos a partir de los cuales los ganaderos definen lo agrario y lo rural: "principal fuente de producción", "palanca de la rehabilitación y del equilibrio económico", "sector básico de la economía nacional", "papel protagónico en la solución de los problemas nacionales", "creciendo la agropecuaria el país entero crecerá", están suficientemente formalizados, conformando representaciones dotadas de "previsibilidad social", situadas por encima de las variaciones individuales y las fluctuaciones temporales. Produce, parafraseando a Bourdieu, "una evidencia ciega en los símbolos".

La utilización de este tipo de representaciones genera "imposibles semánticos" y conducen a la enunciación e interpretación por un sólo camino posible. La imposición de esta codificación es el pleno ejercicio del poder simbólico, por lo que predeterminan los acontecimientos sociales que realizan los agentes a partir de estas categorías de percepción del mundo social del campo agrario. La creación y uso de estas representaciones forma parte del "capital simbólico" de estas gremiales y de la "fortaleza" de las representaciones sobre ellos mismos y sobre la percepción de los demás.

Estas representaciones son la antesala natural de la conformación e 
imposición de una visión del mundo: "ponemos énfasis en el Uruguay agropecuario, este es un país esencialmente agropecuario", "del progreso agropecuario surgirá el del país todo", "el progreso del país está indefectiblemente unido y dependiente de una agropecuaria pujante". Estas representaciones adquieren significación en tanto que dotan a las representaciones de un carácter normativo, que son internalizadas como tales por los agentes sociales a los que están dirigidos (gobernantes, elites políticas, dirigentes y opinión pública en general), formando parte de sus "expectativas sociales" al (re)presentarse la "realidad" del país y sus desafíos sociales, económicos y políticos. Este proceso deriva de la función de imposición de esta "categorización" en las operaciones de percepción y de pensamiento, mediante la simplificación y la uniformidad de la realidad, la que aparece como evidente por el producto de la repetición incesante y del poder simbólico de quien las repite.

La misma "tradición" agraria que ellos evocan tanto en sus prácticas y en el lenguaje son un compuesto de estos elementos simbólicos. La propia Feria del Prado, ${ }^{8}$ los congresos, los expositores, los concursos, la presencia de presidentes, ministros y embajadores, favorecen y legitiman la naturalización de sus representaciones: "La agropecuaria nacional, sin jactancia alguna, se considera el eje vital de la economía del país y nuestra institución a lo largo de casi 120 años de permanente defensa de ella, también sin ninguna clase de jactancia, se siente parte importante como expresión de la misma". La herencia cultural o tradición es, por definición, un proceso de continuidad deliberada, constituyendo una selección y re-selección de aquellos elementos significativos del pasado, recibidos y recuperados, que representan no una contigüidad necesaria sino deseada, que favorece las posiciones de poder del agente, en este caso las organizaciones ganaderas. En este sentido, los deseos no son en abstracto, sino que están efectivamente

8 La Feria del Prado es el principal evento agropecuario del país en el cual se dan cita las principales autoridades de las gremiales ganaderas y del gobierno. Dicho evento, organizado anualmente por la ARU, logra concitar una alta concurrencia de personas que participan de las exposiciones, remates y concursos. 
definidos por las relaciones sociales existentes.

Los discursos de la ARU como prácticas simbólicas (re)crean ritos que favorecen su reconocimiento y consagración como portavoz, dando a sí mismos y recibiendo de los demás en el mismo momento una seña distintiva, un signo de reconocimiento: "tomamos la representación de todos los órdenes y aspiraciones de la ciudadanía; los productores rurales estamos dispuestos a desempeñar el rol que nos corresponde", "pedimos al pueblo, a la ciudadanía, que una vez por todas piense como país agropecuario, se sienta agropecuario, pues eso es lo que fuimos y lo que somos", "el país depende sustancialmente del campo, y todos los habitantes deberían ser conscientes de que en gran medida su suerte está ligada al campo".

Estos discursos son simbólicamente eficientes, en tanto que se realizan en situación de autoridad. Al enunciar lo que se "es", están dando un "veredicto" en su definición social legítima, lo que está "autorizado", lo que tiene derecho "a ser" y a "reivindicar" (Bourdieu, 1995, p. 238). "Uruguay no puede no ser un país agropecuario, como el sector no puede no ser el eje de la economía nacional". Existe de esta manera una sistematización de procedimientos discursivos formales, estables, recurrentes, reconocibles y predecibles, que producen una suerte de simbolización, que por inclusión/ exclusión "anclan el sentido" en significantes invariantes, re-legitimando al designador (ARU y FRU), al papel social del sector y al rol que deben cumplir los productores rurales: papeles y roles que son conocidos y reconocidos como naturales. En otras palabras, éstos son parte de los componentes de las prácticas discursivas de los ganaderos para atesorar y acumular capital simbólico en la sociedad uruguaya.

En este sentido, para que funcionen las "connotaciones" simbólicas se requiere de portavoces que tengan incorporado el sentido del juego social y de la relación de fuerzas del campo, de tal manera que les permita tener la suficiente familiaridad con las costumbres, con el uso del lenguaje, con el trasfondo histórico, con una rica base de información, que pueda 
poner la historia a su favor para garantizar un criterio de verdad convencionalmente aceptado (Van Dijk, 1993). Como claramente se puede observar en los siguientes pasajes de los discursos de la ARU: "la evidencia histórica indica que sin un campo próspero no hay progreso", "al sector agropecuario no hay que mirarlo como un sector más de la producción nacional, sino como el verdadero y único impulsor de toda la economía nacional".

Que el Agro o el Sector Agropecuario estén asociados o sean equivalentes a significantes tales como: "eje de la economía", "auténtica riqueza nacional", "protagonista del progreso y desarrollo", como elementos reiterados y redundantes en los discursos, es la "estrategia de reproducción" puesta en "práctica" para producir y reproducir el capital simbólico. Éste se sustenta en el flujo constante de significados asociados y "extensiones del significado", que permiten aumentar el capital simbólico por captación de elementos de significado adicionales: "del agro en tanto sector principal de la economía, depende la felicidad material y espiritual del país", "el agro es un entusiasta defensor del Uruguay natural".

Es importante también señalar la relevancia de algunos "operadores semánticos" en el contexto del discurso, tal es el caso de las referencias a las personalidades que asisten a los discursos, a las que siempre se "nombra" en el comienzo del discurso: Sr. Presidente de la República, Sres. Ministros, Sres. Embajadores, etc. El remarcar la presencia de estas autoridades, que "representan" al Estado y su gobierno, no sólo son elementos de "distinción" que connotan la importancia del sector, sino que son signos de reconocimiento y consagración del Estado. Por tanto, la misma presencia de estas autoridades es el capital simbólico de los ganaderos, objetivado y garantizado por el Estado. Nombrarlos uno por uno en el discurso deja en claro para los ausentes, para aquellos que no quieren "ver" su poder, como el mismo es consagrado año a año por la máxima autoridad simbólica: el Estado Nación. 


\subsection{Relaciones de oposición y distinción}

Se ha visto en los puntos anteriores como las representaciones simbólicas de las gremiales ganaderas son construidas sobre un determinado número de figuras simbólicas. Dichas figuras les permiten auto-designarse en base al "nosotros somos", pero, como en todo proceso relacional, presentan una oposición con un "otros". Nos detendremos ahora en estas oposiciones, en las luchas entre las estrategias de definición de los principios legítimos de división y distinción del mundo rural y de la sociedad.

La práctica discursiva de las gremiales ganaderas, como toda totalidad estructurada que busca imponerse como hegemónica, tiene también necesariamente elementos de oposición que la componen. La función de las oposiciones, como de las asociaciones ya vistas, es presentar una cadena de equivalencias que pretenden simplificar el mundo social, así como explicar sus problemas en función de enunciados preformativos, rígidos y lineales, como armas fundamentales para la lucha simbólica.

El eje de esta construcción de opciones pasa por un apelo a lo identitario, el "nosotros somos" conformado por los elementos que los "distinguen": campo / riqueza / protagonismo / desarrollo / progreso / felicidad. Este "nosotros somos" fija la existencia de los límites desde los cuales los ganaderos construyen los requisitos de pertenencia y de exclusión a la clase. Esta producción de diferencias es esencial para que exista "significación" de la distinción social y el ejercicio del poder simbólico del grupo. Los límites o fronteras que se representan simbólicamente están asociados y connotados como varios tipos de referentes. En primer lugar, y como el más general, tenemos la opción por negar y menospreciar al resto de la sociedad: "somos los representantes del país en su conjunto y el sector protagonista de la economía nacional", "el agro no precisa de ayuda ni de transferencias de otros sectores", "nacimos cuando nacía este pequeño país, fundado por inmigrantes y orientales, poco después de la Revolución de las Lanzas". 
El exceso de oposiciones simbólicas que frecuentemente han tenido las estrategias de estas gremiales las han obligado a reforzar permanentemente sus discursos y prácticas defensivas frente a los "otros", quienes deben ser continuamente culpabilizados por los "problemas" o "males" que no permiten al sector transitar por la senda del crecimiento y de desarrollo preestablecido por su propia naturaleza.

Un nivel de diferenciación y oposición lo constituye la identificación territorial: campo/ciudad, oposición binaria que produce lejanías y cercanías simbólicas, a través de las cuales las identificaciones se constituyen y se consolidan. Oposiciones simbólicas como "el interior y la ciudad-puerto"; "el interior olvidado en favor de la ciudad"; "la ciudad que se lleva todo el fruto del esfuerzo", "las miradas urbanas que no entienden el esfuerzo de nuestros trabajadores rurales". Estas representaciones contribuyen en la edificación de fronteras, como elementos simbólicos con los que se establecen las distancias y definen la "escénica" de las cosas: "el campo reserva de riqueza a la cual se acude cuando los demás sectores se han agotado en su capacidad".

Esta distinción simplista mantiene una vigencia extraordinaria en las formas de percepción del mundo rural de los distintos agentes sociales en Uruguay. De hecho, ésta se ha ido desplazando cada vez con mayor insistencia a otras opciones más veladas. En función de esta primera y más amplia opción del discurso, se conforma una equivalencia de la ciudad con el Gobierno, la centralización, lo burocrático. "Un Estado hotelero, pesquero, industrial, centralista, burócrata y capitalino es un Estado que transforma las relaciones de fuerza, deja de lado al hombre, al ser humano, la familia, la tierra, el campo y el valor individual". Por consiguiente, los ganaderos estarían junto a las demandas de los gobiernos regionales y locales en búsqueda de mayor descentralización, por la reducción de la burocratización y contra la ineficiencia del Estado y las empresas públicas. ${ }^{9}$ Una segunda particularidad que asumió este desplazamiento de la oposición simbólica campo/ciudad

9 Estos elementos, los que se incorporan en esta cadena de equivalencias, dan un amplio espacio para la articulación potencial de alianzas de los ganaderos con un abanico de fuerzas sociales del "interior". 
fue incluir al sistema político y sus agentes - "los políticos" - como opuesta al campo. Esta oposición ha hecho en muchas ocasiones que el discurso de los ganaderos se transformase en "anti-político", deslizando cuestionamientos sobre las formas de ejercicio democrático en el país. Esta postura les permitirá, en algunas ocasiones, el descontento con el sistema político por la persistencia de problemas que la ciudadanía suponía podían ser resueltos con el advenimiento de la democracia. ${ }^{10}$

Otra línea divisoria del mundo social impuesta por los ganaderos lo constituye la oposición entre el Agro y la Industria. En particular, esta oposición se utiliza reiteradamente en los conflictos de precios con la industria frigorífica, identificando a los empresarios industriales con todas las connotaciones negativas asignadas a los "otros". En este aspecto, los frigoríficos son siempre señalados por lo ganaderos como los "grandes culpables" del estancamiento del sector. A los empresarios de los frigoríficos se los deslegitima como tales, argumentado sistemáticamente que su viabilidad se debe a los privilegios que el gobierno le otorga en perjuicio del interés de los ganaderos.

Sin embargo, fuera del sector cárnico esta oposición comienza a disminuir en la recreación del mito ganadero actual, la raíz de la utilización del concepto de Agroindustria. Este concepto intenta superar la oposición y plantar una estrategia de unificación que busca significar por un lado, los valores positivos de la Industria como crecimiento, desarrollo y empleo, uniéndolos a los valores de la tierra y la agropecuaria. En el contexto actual de pérdida de autonomía y significación de lo "agrario", este nuevo concepto aparece como un recurso valioso para actualizar el discurso de las gremiales.

Esta igualación entre agro y agroindustria se ha ido fortaleciendo, adquiriendo una significación particular que ha hecho más difusa la distinción entre ambos sectores. Esto ha atenuado la oposición entre ambos, mostran-

10 Este será un rasgo más saliente en la FRU, la que llegará a proponer la realización de un plebiscito para reducir a un tercio los representantes del Poder Legislativo, por considerarlo un "gasto innecesario". Si bien esta iniciativa no prosperó, puso nuevamente a estas organizaciones en el margen de lo que puede considerarse como una acción de defensa de sus intereses en el marco de las reglas democráticas. 
do como los "verdaderos intereses de la agroindustria son los productores rurales representados por sus gremiales".

Al interior del propio campo hay también una oposición más velada en función del reconocimiento y la distinción que se organiza en torno a estructuras objetivas (volumen de capital global en sus diferentes especies en el agro): ganadería, agricultura, lechería, productividad, mercado interno o externo, volúmenes de exportación, tamaño de la tierra. Aquí opera una doble acción. Primero y ante todo, negar las diferencias entre productores por tamaño: "es falsa la división entre grandes, medianos y chicos, todos somos productores rurales". Pero, posteriormente, se reivindica veladamente la posición de privilegio de los ganaderos frente a los otros rubros agroindustriales: "el sector ganadero no es sólo un número estadístico, constituye uno de los capitales mayores con que cuenta el país, capital social, capital cultural y productivo", "¿Puede seguirse sosteniendo que la vaca y la oveja no son una de las más preciadas maquinarias con que cuenta el país?".

Cuando las estructuras incorporadas y las estructuras objetivas coinciden, la percepción se hace evidente, el establecimiento de diferencias al interior del campo se codifica, se formaliza, de modo tal que la "ganadería" - determinada por la posesión "de las más preciadas maquinarias como la vaca y la oveja" - es percibida y valorada como jerárquicamente superior frente a otros bienes del mismo campo. Los ganaderos se convierten en un "ser - percibido" de acuerdo a sus propiedades diferenciales; y debido a que las estructuras de percepción y valoración son el fruto esencial de la incorporación de las estructuras objetivas, la estructura de distribución del capital simbólico tiende a presentar una "estabilidad" muy grande (Bourdieu, 1995): "La ganadería ocupa 14 millones de hectáreas, es el sector vital de la economía", "La lana es nuestro principal producto exportable digno de imitar por otros sectores".

Una de las características de la distinción a la hora de la defensa de los "intereses" es que éstos no deben presentarse únicamente con connotaciones relacionadas a la economía, sino también asociados a prácticas estructuradas 
sobre principios axiológicos, con pretensión de universalidad y con "desinterés" de lo estrictamente económico: "espíritu de contribución", "símbolo de voluntad, tesón e inteligencia", "vocación de producir que va más allá de todo razonamiento económico".

Los ganaderos dentro del campo agrario tienen luchas destinadas a mantener, conservar o aumentar el "sistema de diferencias", es decir, la estructura de los diferentes capitales. Si analizamos lo que parece estar en juego en el campo de los conflictos agrarios, los elementos de distinción ligados a la existencia misma del campo y su relación con el campo de poder serían: la "revalorización de la producción ganadera", el "derecho a la propiedad", la "política sectorial", "la rentabilidad", "el libre mercado", "la libertad individual, la iniciativa privada y la desregulación". Estos tópicos representan la definición de los instrumentos y las apuestas para la lucha. Se constituyen como definiciones e instrumentos que van a estar sometidos a las variaciones impuestas por el curso del juego social y que conducen a re-definiciones, replanteos de alianzas, nuevas estrategias y nuevas oposiciones dentro del campo y entre campos.

Dentro del campo social agrario, los intereses específicos de los ganaderos entran en conflicto con los intereses de los otros actores del campo. Frente a ello, se utiliza la estrategia de "condescendencia" hacia agentes agrarios que ocupan posiciones subordinadas; es una estrategia basada en "la negación simbólica de la distancia social, que no deja por eso de existir, asegurándose así las ventajas del reconocimiento acordado en una denegación puramente simbólica de la distancia” (Bourdieu, 1987, p. 132). Los siguientes fragmentos de los discursos son un ejemplo de ello: "Queremos recomendar cautela en la asignación de recursos para la forestación", "la $A R U$ reivindica al sector granjero olvidado y castigado" "especial relación que existe entre empresarios y empleados en la actividad rural donde todos participan por igual en las tareas, viven en un sitio en común, comparten los momentos de descanso (...) forjándose así una relación 'de distancia y 
reconocimiento mutuo' a veces difícil de captar desde un enfoque urbano". También hay otras luchas abiertas como lo sostiene Bourdieu, luchas frontales, en tanto el "saber lo que hay que hacer en una situación determinada" (1987, p. 40) de las élites ganaderas, hace que utilicen en algunas coyunturas todo su poder simbólico acumulado cuando se sienten amenazados, utilizando la "desvalorización": "en un mundo que galopa hacia cambios estructurales nuestros políticos van al trote", "el clientelismo sigue tan vital como en sus mejores épocas", hacen referencia a la "incapacidad del sector industrial" y a las "burocracias ineficientes". La estrategia frontal es utilizada con más frecuencia por la FRU que por la ARU, más proclive a utilizar estrategias de condescendencia.

Las diferencias y las afirmaciones de su posición en la sociedad, también se proyectan en el tiempo y en el espacio de referencia, incorporando la memoria social: "debemos hacer honor a las generaciones que nos han precedido y proyectar al país al siglo XXI", "rescatemos lo mejor de nuestro pasado, evoquemos el sacrificio de nuestros mayores y en su ejemplo forjemos el futuro de nuestros hijos". Esto permite ordenar la temporalidad en una red de señales figurativas, simbólicas y objetivas, en relación con las cuales el "nosotros" toma su propio relieve y establece entidades categóricamente excluyentes con los "distintos" y "otros".

\subsection{La imposición de su visión del mundo rural}

En los puntos anteriores se señalaban las relaciones asociativas y oposición entre significante y significados, en la prédica de las gremiales ganaderas para imponer su punto de vista sobre el mundo rural. Es este proceso el que les permite la "construcción social de la realidad rural" en función de su "punto de vista". Para que la convención, "el país depende del Agro", funcione simbólicamente, este significado debe ser admitido de forma tal que - aún sin importar la corrección o precisión del mismo en la realidad objetiva - los agentes involucrados en y fuera del campo social sean 
capaces de enlazarlos de forma constante o invariante. De esta forma, la convención incluso se puede convertir en "enciclopedia", "es decir en una representación que permite registrar enciclopédicamente una serie de condiciones que le dan veracidad al mundo representado" (Eco, 1990, p. 130); y no sólo en conocimiento de sentido común, sino además en conocimiento técnico y científico: "El Uruguay, por sus condiciones naturales, es un país agropecuario".

Con este tipo de afirmaciones rotundas, inapelables, se funda la visión del mundo rural que se construye en gran medida inconscientemente sobre los hábitos lingüísticos, los símbolos y convenciones del lenguaje aceptados y utilizados por este grupo social. Los mismos modelan la percepción e interpretación del mundo físico y social, condicionando conductas y comportamientos en el resto de los agentes. Al "decir" como hay que "ver" el mundo se logra, como por arte de magia, efectos reales al moldear comportamientos y acciones logrando determinar, en el caso particular que estudiamos, a los agentes agrarios y a los hacedores de las políticas agrarias.

Como se sabe, el sector agropecuario objetivamente tiene peso en la economía nacional, lo que constituye su capital económico - aunque viene reduciéndose históricamente -, en tanto que los individuos o los agentes corporativos "creen" que lo tienen y "saben" que otros creen lo mismo. Son estas convicciones los soportes de una determinada "concepción de la realidad" construida en base a acuerdos de significados comunes - objetivos y subjetivos -. Al poder afirmar que "el Uruguay se salva con el agro o con él perece" se construye un orden simbólico que se asienta sobre su imposición al conjunto de los agentes, de estructuras cognitivas.

En este sentido, estas convenciones son la génesis de los "roles sociales" de la ganadería y de los ganaderos, normativamente aceptados y legitimados. Las representaciones de cualquier tipo o grupo en concreto pueden ser auténticas o no, pueden ser fidedignas o engañosas, pero en definitiva se internalizan como objetivamente válidas y se aprehenden como realidad. Esta clase de conocimientos - "el Uruguay se salva con el agro o con él 
perece" - son los que "todos saben" sobre el agro. Este conjunto de valores, creencias y mitos, que se forman en los discursos de los ganaderos, son los que crean el universo simbólico que ellos impusieron, constituyendo la dinámica motivadora del comportamiento institucionalizado, la que define y construye los roles que han de desempeñarse en los contextos concretos. De esta forma, es como dichos conocimientos funcionan como un cuerpo de verdades válidas acerca de la realidad, legitimando el orden establecido.

En consecuencia de lo anterior, los funcionarios públicos de distintos rangos que actúan en las múltiples instancias en que se deciden las políticas públicas para el sector, así como los políticos que tratan los marcos normativos, están predispuestos en menor o mayor medida por esta "mirada" del mundo rural, lo que motiva la dinámica de los comportamientos institucionalizados en el sector creando las condiciones para su perpetuidad social. En consecuencia, la definición de los problemas y las propuestas de soluciones para el sector se realizan en el marco de una realidad agraria construida desde el punto de vista de los ganaderos. Este es el punto de partida de la eficacia de su acción colectiva.

\section{Poder simbólico y el Estado}

Como ya se ha soslayado en los puntos anteriores, el análisis de las estrategias simbólicas no puede omitir las luchas por el poder del estado que despliegan las gremiales ganaderas y el Estado. Como señala Bourdieu (1992, p. 124) el estado es "la sede por antonomasia de la concentración y del ejercicio del poder simbólico" y "el único que está en condiciones de regular el funcionamiento de los diferentes campos y de cambiar las reglas del juego". La lucha por el poder sobre el Estado se funda en el reconocimiento de la capacidad estatal de desequilibrar la "tasa de cambio" entre los capitales de los distintos campos, de afectar el volumen de los diferentes tipos de capital y, en consecuencia, de generar impactos negativos sobre las estrategias 
específicas de "reproducción" de los ganaderos. Su prédica discusiva por reducir las funciones del Estado, es el medio por el cual las gremiales ganaderas propenden a la conservación de su patrimonio económico y a la consolidación de su poder simbólico para mantener su posición en el campo. ${ }^{11}$ La imposición de su punto de vista depende, en gran medida, de lograr imponer también una nueva visión sobre el funcionamiento del Estado. Los argumentos de las gremiales en este sentido, son de este tipo:

En el mundo de hoy la agresividad y competitividad de los mercados de producción agropecuaria exige el libre juego de la oferta y la demanda, mecanismo idóneo para la orientación de la actividad económica. Cuando se libera una guerra comercial despiadada a nivel internacional, no podemos darnos el lujo de mantener transferencias intersectoriales. Todos en el país tenemos claro que a lo que estamos aspirando es a un sistema de mercado en el cual el Estado pueda ser un elemento orientador sin que represente una asfixia.

Las luchas por el poder sobre el Estado se manifiestan en un estado concreto de las relaciones de fuerza, por la distribución o redistribución de los "beneficios". En este sentido, los ganaderos advierten: "Se terminó la época del Estado paternalista, empleador de mano de obra y generador de discriminaciones". Pero a la vez exigen para ellos una especial atención: "es extremadamente peligroso desarmar la estructura de un país productivo, por modas pasajeras no mayoritariamente aceptadas, conformando un país de servicios y prescindiendo de los sectores productivos", y que "estamos dejando de ser un país agroexportador y convirtiéndonos en un país de servicios. ¿Es eso lo que queremos? Los productores no lo creemos así y no nos resignamos a dejar nuestros campos y dejar de producir".

Para ir imponiendo paso a paso esta constelación de ideas sobre el

11 La favorable inserción internacional de sus productos (carne y lana) y su bajo nivel de elaboración, han hecho que sus intereses dependan en gran medida de la captación que el Estado, por distintas vías, realiza de sus excedentes. 
papel del Estado, en este período se comienza también a cuestionar las políticas re-distributivas, buscando deslegitimar los impuestos a las ganancias, reclamando en su discurso como una máxima universal que "es justo y legítimo que quien trabaja, invierte y arriesga pretenda recibir también con justicia y legitimidad lo que ese trabajo genera", "La extraordinaria dimensión del Estado no sólo implica una carga insoportable para el productor, para el industrial y el comerciante, sino que en definitiva atenta contra la libertad del individuo".

La lucha por la "transformación del Estado" se coloca, de esta manera, para los ganaderos, como una condición sine qua non para sus intereses como estrategia de conservación de sus diferentes tipos de "capitales", los que re-presentan y re-definen al sector agrario. En este sentido, ellos pondrán en juego su poder, atesorado en luchas anteriores, históricas: "Hicimos el Código Rural, alambramos los campos, trajimos razas, construimos la Nación". Esta Ostentación de signos busca legitimar sus enunciados de que el Estado vuelva a ser un Estado para la Nación = Agro, y por tanto es necesario cambiar las reglas del juego: "El país renegó de su vocación agropecuaria". Con esto expresan su desilusión, su pérdida, el desequilibrio, en tanto afecta sus capitales tangibles - propiedad y rentabilidad -, y al capital simbólico reconocimiento y consagración - en favor de otros sectores de la economía.

Sostiene Bourdieu que una posición simbólica de cercanía - es decir de reconocimiento mutuo entre los agentes involucrados - en la lucha del poder, proporciona mayores posibilidades - a los más cercanos y reconocidos - de imponer nuevas reglas de juego, de re-instituir el Estado sobre la base de sus intereses específicos y mediante "estrategias de valoración": "del campo sale todo lo necesario para la vida del país"; así como también, mediante "estrategias de desacreditación", intentando cambiar el valor relativo del capital de otros campos: "incapacidad del sector industrial o ineficiencia de las burocracias", "nos hemos criado bajo un proteccionismo que ha llegado a obnubilarnos y anular nuestra creatividad". Esta táctica discursiva del "yo acuso, yo exijo", es el resultado y la realización del proceso de "emancipación", que en determinada coyuntura histórica rompe con cierto orden establecido: el Estado 
Benefactor, la Economía proteccionista cerrada e industrial, postulando nuevos valores. Se enuncian como verdades absolutas, como el único camino posible para la "libertad" del hombre - valor universal -, que por ser quiénes son y por tener lo que tienen - reconocimiento y legitimidad -, pueden erigirse como custodios de estos valores simbólicos. Su punto de vista particular se presenta y se impone como punto de vista universal y buscan constituir su punto de vista en tanto que punto de vista universal estableciendo el Estado (Bourdieu, 1994, p. 121).

Para los Ganaderos, el Estado debe dejar de ser "Todopoderoso", sobre todo cuando se opone a sus intereses particulares. Se requiere de un "Estado testigo y no agente, custodio de los servicios primarios y guardián para la función del orden, tutelador de la libertad, estimulador de la libre empresa y defensor de la libre iniciativa, el concepto de Estado liberal". En definitiva, un Estado que garantice cabalmente sus intereses particulares universalizados y no amenace la reproducción social del grupo.

En la lucha por el poder y la definición y redefinición de sus "intereses", los impuestos son un tópico central y recurrente en sus discursos relacionados al Estado. Éstos son manejados como las "armas (del Estado) que destruyen a la actividad agropecuaria", pero que a su vez funcionan como elementos esenciales para la reproducción y representación simbólica de un Estado con autoridad, del cual ellos también necesitan. Señala Bourdieu, que los impuestos basan su legitimidad y su consentimiento en cuanto representen a la colectividad en su conjunto. Pero como hemos visto en el corpus discursivo del sector ganadero, mediante el trabajo de inversión ellos se consideran como los representantes de la comunidad en su conjunto y en tanto los impuestos son para "intereses privados" - burocracias, frigoríficos, empresas públicas, seguridad social -, los transforma en "no legítimos".

El hombre del campo es consciente que el Estado necesita de su contribución, pero también sabe que los números rompen los ojos, siente que el gobierno de su país lo 
está impulsando a una situación que pierde el trabajo de años. La vorágine de la modernización y la fiebre estatizante ha encandilado, esperamos todo del Estado, heredamos bienestar y nos olvidamos de los métodos que se habían utilizado para obtenerlos. Las transferencias de recursos son el mayor perjuicio causado a los productores por la acción del Estado (1994, p.100).

La FRU es aún más directa en su lucha frente al Estado, desplegando contra él una estrategia de confrontación directa:

ratificamos la histórica postura de la más absoluta libertad de mercado, sostenida y mantenida sin claudicaciones, la constante transferencia intersectorial y las políticas proteccionistas han afectado nuestra rentabilidad. Cuando se obsequió a la industria aceitera para que le cerraran las cuentas con 2 millones de dólares o cuando se atendió a la industria frigorífica con cantidades aún superiores, o se asistió a bancos con decenas de millones,

en cambio, se afirma que "los productores se debaten hoy en un sacrificio sistemático para poder subsistir".

Las estrategias discursivas respecto a la presión fiscal que soporta el sector están destinadas a "hacer ver y valer" ciertas realidades. Las palabras, los nombres que construyen la realidad social tanto como la expresan, son la apuesta por excelencia de la lucha política y las "estrategias" en sí mismas suponen "invención" permanente (particular, universal, social, natural, etc.), condición que es indispensable para adaptarse a situaciones nuevas. "El Estado debe abocarse a administrar mejor sus recursos y adoptar políticas responsables y coherentes con el país y con el agro". "Se requieren condiciones que prioricen lo productivo frente a lo especulativo y burocrático".

En síntesis, la forma simbólica constitutiva del mito de "país ganadero", Ganadería $=$ País $=$ Nación, está en condiciones de funcionar también para Estado $=$ Nación $=$ País $=$ Ganadería , y por tanto, quienes ostentan 
este "capital simbólico" tienen un capital de reconocimiento y consagración, prestigio, legitimidad y "autoridad", como para imponer nuevas reglas de funcionamiento al Estado.

\section{Conclusiones}

La reconstrucción que las gremiales ganaderas hicieron del Mito del País Ganadero, como eje de su estrategia para recuperar su poder simbólico en la sociedad y garantizar su reproducción social, estuvo basada en cuatro componentes simbólicos básicos: la Tierra, la Ganadería, el Productor Rural y la Acción Gremial. Éstos constituyen, estructurados en la cadena de sentido que se ha señalado, la fuerza simbólica de su discurso. Con este poder simbólico fueron creando las oportunidades para imponer su visión del mundo rural como universal, recreando de este modo su hegemonía en el campo social agrario y avanzando en sus posiciones en el campo de poder frente a las otras fracciones dominantes.

El primero de esos componentes, "la Tierra", adquiere un significado que nos remite directamente a las teorías fisiócratas, el que otorga a la producción agropecuaria un rol fundamental en la sociedad como "principal fuente de riqueza", "única y auténtica ventaja comparativa del país", de donde "sale todo lo necesario para la vida", "reserva inagotable de recursos" y "fuente de felicidad material y espiritual de la sociedad", "una reserva moral para el país". Este rol protagónico que la ARU y FRU atribuyen a "la tierra" enviste de un incuestionable poder simbólico a quienes Ilevan delante la "noble" actividad de hacerla producir: el "Productor Rural", segundo elemento constitutivo del Mito del País Ganadero.

El Productor Rural (usado como sinónimo de ganadero), nos dibuja la imagen de un agente social idealizado, portador de "lo bueno", criticado y presionado sin fundamentos. Se caracteriza en estos discursos por ser "injustamente acusado", con "vocación de producir más allá de los cálculos 
económicos", con "fe en el agro". Todo ello induce a pensar en un agente con acciones "esforzadas", a la altura de la importancia de su "rol" en una sociedad que se manifiesta como el producto de los "recursos que maneja", lo que lo llevaría a actuar de manera no muy racional, "con fe" "más allá del cálculo económico". Estos argumentos sirven para justificar que su acción no sea comprendida por los agentes sociales que no tienen sus responsabilidades. Este sitial de "incomprendidos" les permite resguardarse de las reiteradas acusaciones de hacer un mal manejo empresarial de los recursos naturales que poseen. En ocasiones, esta "especificidad" también les permite un argumento para transformarse en una excepción de las reglas de mercado que ellos entusiastamente impulsan para el resto de la economía.

Usando la equivalencia entre las virtudes de la tierra y quien la posee, le atribuyen a estos últimos valores altruistas y generosos asociados a su "noble" actividad de hacer producir a la tierra riqueza "para" el país. Por tanto, extendiendo estos conceptos a las ganancias y los intereses materiales de los ganaderos, sus acciones no pueden ser comprendidas como actos egoístas, de un grupo social poderoso contra otros grupos con menor poder. En esta visión del mundo, los intereses y ganancias de los ganaderos son transformados simbólicamente en "justas y legítimas retribuciones al esfuerzo de su trabajo".

El tercer elemento constitutivo de la estrategia simbólica para recrear el mito del país ganadero es la Ganadería. Bajo la designación de sector Agropecuario se agrupan indistintamente las actividades que se desarrollan en el sector agrario. La ambigüedad de este término lleva a que nunca se sepa con certeza si sus afirmaciones son sobre el sector tradicional o también involucran las actividades agroindustriales. Esta estrategia discursiva, ampliamente utilizada por los dirigentes gremiales, busca incorporar los logros de los sectores agroindustriales, objetivamente dinámicos, como logros alcanzados por el conjunto del sector, atribuyendo a las actividades ganaderas una difusa capacidad dinámica muy difícil de contrastar objetivamente. Las afirmaciones sobre el "Sector" o el "Agro" se confunden con los valores atribuidos a la tierra y a la ganadería - original- 
mente acuñadas en el combate contra las visiones reformistas y agraristas de principios del siglo XX, con referencia exclusiva a la actividad ganadera - y que aparecen hoy como deslizadas "naturalmente" a los nuevos sectores agroindustriales: "el Uruguay se salva con el agro o con él perece", "el progreso del país depende del progreso del Agro".

De esta forma, se pasa a afirmar vehementemente que "el progreso" del país, su "rehabilitación y equilibrio económico", "la creación de empleo", en fin, la "solución de los problemas nacionales, depende de este eje vital de la economía nacional", porque lo que "siembra el agro lo recoge el país". Con esta construcción del mundo se realiza una inversión simbólica de tal magnitud - nos permite observar el volumen de capital simbólico acumulado por las gremiales ganaderas -, que hace posible enunciar este tipo de afirmaciones: "todos los hombres de este país deberían estar conscientes de que en gran medida su suerte está ligada al campo".

El cuarto elemento constitutivo de este Mito Ganadero es la propia acción gremial de sus Instituciones (ARU y FRU). Ésta, de alguna manera sintetiza los significados, la acción y la legitimidad de los otros elementos y los expresa de manera colectiva al conjunto de la sociedad. Como afirma el presidente de la ARU, "su acción gremial continua y trascendente" desde hace 125 años, provoca que la institución esté

indisolublemente unida al destino de la nación desde su propio nacimiento. Nacimos exactamente después de la Revolución de las Lanzas, fuimos fundados por orientales y emigrantes, eran gente de estratos diferentes, pero con un ideal común, creían y querían a la agropecuaria y por ello formaron una institución dispuesta a trabajar por el agro y el trabajador rural (...) cuando nacía un pequeño país que se abría camino a ponchazos, rodeado de gigantes sin tener ideas muy claras aparte de ser libres.

Fundada su acción en esta legitimidad histórica pueden recordar que 
con el "espíritu de contribución que ha caracterizado a la $A R U$ (...) siente (la) responsabilidad de proponer caminos de desarrollo nacional, (...) (para) proyectar al país al siglo XXI comprometiéndonos a trabajar por un futuro mejor para las futuras generaciones".

De esta manera, su estrategia simbólica naturaliza y universaliza la representación que ellos mismos llevan adelante y les permite un capital simbólico capaz de igualarse con el propio del Estado Nación. Por esta razón, la ARU se siente con el derecho, a fines del siglo XX, de pedir en un acto de supremo poder simbólico que el "pueblo y la ciudadanía se sienta agropecuaria, pues eso es lo que fuimos y lo que seremos", afirmando además, que toma "la representación de todos los ordenes y aspiraciones de la ciudadanía”. Esta inversión sin igual, por la cual la ARU pasa de representar a los ganaderos a representar a toda la ciudadanía, constituye la conversión definitiva de sus intereses particulares en "universales", logrando que los intereses de los ganaderos sean los intereses de la ciudadanía.

De esta forma, la acción gremial de la ARU y de la FRU, vinculando en una cadena de equivalencias los cuatro elementos que se han señalado, logran ofrecer una comprensión del mundo rural integrada, creada a partir de sus intereses particulares y que impone a la sociedad la creencia o mito de que el país debe privilegiar al sector ganadero como eje de su desarrollo.

Pero, entrelazado a esta reafirmación del mito del país ganadero, la estrategia simbólica de las gremiales se conjugó con su apoyo irrestricto al discurso neoliberal logrando, como se ha mostrado, unificar su defensa del país ganadero con la defensa de los principios neoliberales, especialmente en referencia al papel del Estado. Esto los llevó durante este período a que muchas fracciones dominantes y de los partidos tradicionales encontraran en ellos un aliado para enfrentar públicamente a las propuestas alternativas al modelo neoliberal. Ninguna de las otras facciones - como los banqueros, el sector comercial, de servicios y otros sectores exportadores - que representaban un poder económico muy superior al de los ganaderos, podía 
hablar con tanta pretensión de legitimidad envistiéndose en representantes de los intereses "del país", de los "ciudadanos de esta tierra", de "los verdaderos productores de la riqueza nacional". Estas no son meras frases sino son enunciados eficientes, que son posibles de "decir" gracias a que se han vencido en el campo simbólico a sus adversarios que cuestionaban su envestidura. Es el uso del capital simbólico no como un mero reconocimiento frente a los adversarios sino como prácticas del poder simbólico sobre los otros agentes.

En resumen, la estrategia simbólica que hemos esbozado les permitió a las gremiales ganaderas mantener en pie la matriz básica del mito de país agropecuario, que a mediados de los 80 corría serios riesgos de pasar a ser un artefacto simbólico obsoleto, anticuado y anacrónico. Su capacidad estuvo en llevar hasta sus límites las posibilidades de elasticidad semántica de la realidad social y re-adaptar eficazmente su mito ganadero a las exigencias del mundo contemporáneo. En suma, en el marco de una fuerte reestructuración de las relaciones de poder que la sociedad uruguaya atravesó en las últimas dos décadas, estas gremiales lograron, además de que fueran considerados sus intereses inmediatos, alcanzar un logro más estratégico: imponer un nuevo concepto de "lo agrario" y "lo rural", legitimando así las medidas que se toman a su favor. Esa re-conceptualización de lo agrario se ha acuñado bajo los argumentos y evidencias fragmentarias que "impone" la globalización del mundo y nos propone ver lo agrario como el problema de las empresas agrarias y de su rentabilidad. Esta perspectiva, ligada estrechamente al discurso economicista dominante del neoliberalismo, logra producir una imagen de "lo agrario" donde es posible separar radicalmente los problemas sociales de los problemas técnico-económicos y, por tanto, como efecto de esta separación, deslindar las responsabilidades de los sectores dominantes de los problemas sociales del medio rural y contribuir eficazmente al ocultamiento del problema.

De esta forma se ha confluido en la construcción de una imagen que 
lo resalta como motor legítimo de la economía donde radica el verdadero potencial del país reprimido tantas veces por el voluntarismo estatista. El eje de esta re-definición pasa principalmente por imponer una separación definitiva entre la cuestión social y la cuestión económica en los problemas agrarios. Esto transformaría lo agrario y lo rural en un "mundo de empresa", donde la competitividad y la rentabilidad serían las únicas claves posibles para su interpretación, llevando a que el sector pierda cualquier especificidad frente al resto de los sectores de la economía.

La fervorosa defensa del sector que hacen estas organizaciones ha ido atravesando a amplias capas de la sociedad, sin tener un correlato en lo material que lo justifique. La imagen del latifundista o terrateniente se ha diluido - aunque la estructura agraria se mantiene casi sin modificaciones desde el siglo XIX - y se ha instalado la imagen de un empresario rural preocupado por la rentabilidad de su negocio, muy alejado simbólicamente de las prácticas de dominación local tradicionales que generaban situaciones sociales problemáticas. Sin embargo, en las últimas décadas se han profundizado los problemas sociales, con la desaparición de casi el 30\% del total de los establecimientos familiares y las desigualdades sociales se han incrementado, llegando a ser las de mayor magnitud en el país, puesto que la mitad de los trabajadores rurales y los agricultores familiares viven en condiciones de pobreza.

\section{Referencias}

ANSART, Pierre. Las Sociologías Contemporáneas. Buenos Aires: Amorrortu, 1992.

ASTORI, Danilo. La Evolución Tecnológica de la Ganadería Uruguaya 19301977. Montevideo: EBO, 1979.

BARRAN, J; NAHUM, B. Batlle. Los Estancieros y el Imperio Británico. Tomo II. Montevideo: Ediciones de la Banda Oriental, 1981. 
Sociologias, Porto Alegre, ano 6, no 11, jan/jun 2004, p. 184-218

BARDIN, Laurence. Análisis de contenido. Madrid: Akal, 1986.

BOURDIEU, Pierre. Cosas Dichas. Buenos Aires: Editorial Gedisa, 1988.

BOURDIEU, Pierre. Cosas Dichas. Barcelona: Gedisa, 1993.

BOURDIEU, Pierre. Las Reglas del Arte. Barcelona: Ed. Anagrama, 1995.

BOURDIEU, Pierre. La Noblesse D'État. Paris: Ed. Minuit, 1989.

BOURDIEU, Pierre. La Distinción: Criterios y Bases Sociales del Gusto. Madrid: Ed. Taurus Humanidades, 1991.

BOURDIEU, Pierre. Razões Práticas; Sobre a teoria da Ação. Campinas: Ed. Papirus, 1996.

BOURDIEU, Pierre. O Poder Simbólico. Rio de Janeiro: Bertrand Brasil, 1989.

BOURDIEU, Pierre. ¿Qué es lo que hace una clase social?: Acerca de la existencia teórica y práctica de los grupos. Revista Paraguaya de Sociología, Asunción, no 89, Enero/Abril, 1994.

BOURDIEU, Pierre; CHAMBOREDON, Jean Claude; PASSERON, Jean Claude. EI oficio de sociólogo. 19a ed. Madrid: Editora Siglo XXI, 1995.

BOURDIEU, Pierre; WACQUANT, LoÏc. Respuestas. Para una Antropología Reflexiva. México: Grijalbo, 1995.

DE SIERRA, Gerónimo. Los Pequeños Países de América Latina en la Hora Neoliberal. Venezuela: Nueva Sociedad, p. 17-38, 1994a.

DE SIERRA, Gerónimo. (Comp.) Sobre los problemas de (in)gobernabilidad en el Uruguay neoliberal de la posdictadura. In: Democracia emergente en América del Sur. México: UNAM, p. 207-228, 1994b.

DOS SANTOS, José Vicente. Globalização e Conflitualidade no Cone Sul. In: PIÑEIRO, D. (Comp.). Globalización, integración regional y consecuencias sociales sobre la agricultura. Montevideo: AUGM, UNESCO, UR, p. 89-107, 1996. 
Sociologias, Porto Alegre, ano 6, no 11 , jan/jun 2004, p. 184-218

DURKHEIM, E. As formas elementares da vida religiosa. In: RODRIGUES, J. (Org.). Emile Durkheim: sociología. 2a. ed. São Paulo: Ática, 1981.

EAGLETON, Terry. Ideología. Uma introdução. São Paulo: Boitempo, UNESP, 1997.

ECO, H. Semiótica y Filosofía del Lenguaje. España: Ed. Lumen, 1990.

FOUCAULT, M. Las Regularidades Discursivas. Montevideo: Comunidad Sur, 1986.

FOUCAULT, M. Microfísica del Poder. Madrid: La Piqueta, 1980.

GÓMEZ, Sergio. El marco conceptual para el estudio de las organizaciones empresariales rurales. Revista Paraguaya de Sociología, año 31, no 89, p. 179205, Abril. 1994.

GÓMEZ, Sergio. Nuevos sectores dominantes en la Agricultura Latinoamericana. Estudios Rurales Latinoamericanos, v.12, no 1, 1989.

GUBERT, R. La mirada opulenta. Exploración de la iconosfera contemporánea. Barcelona: Ed G. GILI, 1994.

JESSOP, Bob. The capitalist State and the Rule of Capital: Problems in the Analysis of Business Associations. Western European Politics, v. 6, no 2, p. 139-62, April. 1983.

KLIPPENDORFF, K. Metodología de Análisis de Contenido. Barcelona: Ed. Paidós Comunicación, 1990.

LANDOWSY, E. La Sociedad Figurada. Ensayos de Sociosemiótica. Barcelona: Ed. Paidós Comunicación. 1993.

MOYANO, Eduardo. Acción Colectiva y Cooperativismo en la Agricultura Europea. Madrid: MAPA, 1993.

NAVARRO, P; DÍAZ, C. Métodos y Técnicas Cualitativas. Madrid: Ed. Síntesis, 1995.

ORTIZ, Renato; BOURDIEU, Pierre. Grandes Cientistas Sociais, São Paulo, no 39, Ática. 1985.

PÉREZ YRUELA, Manuel; GINER, Salvador. Corporativismo: el estado de la cuestión. Revista Española de Investigaciones Sociológicas, no 31, p. 9-45, Julio/Septiembre, 
1989.

PINTO, Céli. O poder e o político na teoria dos campos. Veritas, v. 41, no 162, p. 221-227, Junho, 1996.

PIÑEIRO, Diego. (Comp.) Nuevos y viejos actores para la Modernización Agraria. Montevideo: CIESU, 1992.

POULANTZAS, Nicos. Estado, poder y socialismo. 7a. ed. Madrid: Siglo XXI, 1987.

RIELLA, Alberto. Corporaciones Ganaderas, Poder y Luchas Simbólicas en el Uruguay Contemporáneo. 2002. Tese (Doutorado em Sociologia) - Instituto de Filosofia e Ciências Humanas, Universidade Federal do Rio Grande do Sul, Porto Alegre.

RIELLA, Alberto. Organizaciones Agrarias e Integración Regional: la Construcción Social del MERCOSUR. Revista de Ciencias Sociales, Montevideo, Departamento de Sociología - Facultad de Ciencias Sociales, 2003.

RIELLA, A. y TUBIO, M. (Comp.). Empleo rural y Transformaciones Agrarias. Montevideo: FCS-DS-RN, 2001.

VAN DIJK, R. Texto y Contexto. Semántica y Pragmática del Discurso. Barcelona: Ed. Cátedra, 1993.

DISCURSOS DE LOS PRESIDENTES DE ARU Y FRU en sus respectivas Exposiciones y Congreso Anual. Versiones Mimeógraficas. De 1985 a 1999.

Recebido: 01/04/2004

Revisado: 19/04/2004

Aceite final: 28/04/2004 


\section{Resumen}

En este artículo se buscará estudiar el amplio poder de influencia que los grandes estancieros y sus gremiales logran mantener desde hace más de un siglo en el Uruguay. Mediante el análisis de la dimensión simbólica del mundo social agrario estudiaremos las prácticas discursivas de las Gremiales Ganaderas Asociación Rural del Uruguay y Federación Rural - como parte central de su estrategia simbólica para mantener su hegemonía en el campo social agrario. En este sentido, creemos que la construcción social del territorio en nuestro país se asienta en la forma de percepción impuesta por el poder simbólico de este grupo que ha hecho de sus formas particulares de apropiación y uso de la tierra la única forma posible y legítima de utilización de los recursos naturales. Para el análisis de las prácticas discursivas partimos del supuesto de que las organizaciones sociales, gremiales y corporativas están siempre inmersas en luchas simbólicas, ya que en ellas está en juego la realización objetiva de sus intereses a largo plazo. Utilizando los términos de Merton, podríamos afirmar que, más allá de la función manifiesta de una organización - gremial, comercial, profesional -, siempre hay una función latente que procura imponer a sus adversarios y a la opinión pública la "visión del mundo" propia del grupo que representa. En consecuencia, en las prácticas discursivas de estos agentes podremos encontrar claramente expresado su poder, sus alianzas, sus conflictos, lo que nos permite acceder a la comprensión de su estrategia simbólica de reproducción social.

Palabras-clave: conflictos sociales, poder y dominación, poder simbólico, sociología rural, uruguay. 